\title{
Proceeding
}

Supplementary Issue: Spring Conferences of Sports Science. International Conference on Psychology of Education Sciences \& Lifestyle.

\section{The improvement of athletes' competitiveness assessment as an element of sports legal regulation in the Russian Federation}

\author{
OLGA ALEXANDROVNA SHAVANDINA $\triangle$, EKATERINA YURYEVNA KOVALENKO, NINA IVANOVNA \\ PRATSIUK
}

Altai State University, Barnaul, Russian Federation

\begin{abstract}
The article is devoted to the issue of the improvement of athletes and sports organizations' competitive-ness assessment in order to justify the necessity of its (competitiveness) legal regulation. The findings of foreign and domestic studies have contributed to the development of integrated model in order to assess the competitiveness of athletes and sports organizations. The results of its adaptation confirm the apodictic character of the model. A comparative analysis of the sports legal regulation in Europe and Russia has underscored the necessity of legal regulation in the sphere of registration and provability of the results of athletic achievements. However, it is notable that the scientific works are primarily devoted to the analysis of sports achievements and exclude the assessment of athletes' competitiveness. Thus, the assessment of athletes' competitiveness will contribute to their promotion in "sports market" and influence the competitiveness of a sports organization.

Keywords: Athletes; Competitiveness; Sports relations; Legal regulation; The Russian Federation; Sports clubs.

\section{Cite this article as:}

Shavandina, O.A., Kovalenko, E.Y., \& Pratsiuk, N.I. (2020). The improvement of athletes' competitiveness assessment as an element of sports legal regulation in the Russian Federation. Journal of Human Sport and Exercise, 15(3proc), S856-S868. doi:https://doi.org/10.14198/jhse.2020.15.Proc3.37
\end{abstract}

Corresponding author. Altai State University, Barnaul, Russian Federation.

E-mail: shavandina.olga@yandex.ru

Supplementary Issue: Spring Conferences of Sports Science. International Conference on Psychology of Education Sciences and Lifestyle.

JOURNAL OF HUMAN SPORT \& EXERCISE ISSN 1988-5202

(c) Faculty of Education. University of Alicante

doi:10.14198/jhse.2020.15.Proc3.37 


\section{INTRODUCTION}

Nowadays, sport has become an innately complex system, and it is necessary to consolidate the efforts of the state as well as the sports community to undertake its development. At a meeting of the Council for the Development of Physical Culture and Sports on May 24, 2017 Putin emphasized: "The main thing is to educate a healthy younger generation, which should share the values of an active lifestyle and physical culture ... Our goal is to ensure the competitiveness of Russian athletes and all Russian sports, as well as to maintain leading positions in numerous areas." In order to accomplish this goal, sports professionals would be required to ensure the following: legal regulation, economic support and sports infrastructure.

However, the assessment and legal regulation of the athletes' competitiveness (sports organizations) are not impervious to challenges. In this regard, it is necessary to provide the following:

- A comparative analysis of the legal regulation of sports relations in not only the Russian Federation, but also the EU (Pijetlovic, 2017; Schulenkorf, 2017; Weatherill, 2014; Peachey, Schulenkorf, Hil, 2019; Siekmann \& Soek, 2012; Van Kleef, 2014; De Dycker, 2019 ; Di Marco, 2019; Alekseev, 2018; Gosteva, 2018; Korchagin, 2015; Bratanovsky, Vulakh, 2015; Saraev, 2019; Iglin, 2014);

- The evaluation of the linkage between the legal regulation of sports relations and the competitiveness of athletes in the EU and the Russian Federation (Voevodina, 2018; Beanland, 2014; Callaway, 2014; Koryagina, Nopin, Blinov \& Blinov, 2015; Ohtonen, Ruotsalainen, Mikkonen, Heikkinen, Hakkarainen, Leppävuori \& Linnamo, 2015);

- The analysis of both domestic and foreign approaches to determine the factors characterizing the individual achievements of athletes (Malcata \& Hopkins, 2014; Matveev, 2019; Kim, Do Kim \& Lee, 2019; Yagodin, 2016; Gill, 1986; De Bosscher, De Knop, van Bottenburg , Shibli \& Bingham, 2009);

- The substantiation of the assessment of athletes' (sports organizations) competitiveness (Hollander, Wolfe \& Chicken, 2014; Corder \& Foreman, 2014; Egoshin, Ivanov, Savvina, Kalmakhanov, Zhamaliyeva \& Grjibovski, 2018; Grjibovski, Ivanov, Gorbatova, 2016; Shavandina, Vasilev, Philippova \& Kiryushina, 2019);

- The substantiation of the necessity of legal regulation of the athletes' (clubs, sports organizations) competitiveness (Voevodina, 2018; Korchagin, 2015; Bratanovsky, Vulakh, 2015; Saraev, 2019; Shchepakin, Krivosheeva, 2015).

The solution of these problems requires a comprehensive analysis in terms of both legal and economic sciences. According to legislation, public (sports) relations become legal relations, the structure of which includes subjects, object and content. The competitiveness is the most important characteristic of the subject of sports relationship, i.e. athlete. The economic aspect of athlete's competitiveness assessment contributes to the promotion of the athletes in the "sports market" and influence the competitiveness of the sports organization as a whole.

The paper is divided into several sections as follows: Section 2 presents a review of the literature, and Section 3 outlines the methods of the research. Section 4 describes the data collection, processing, analysing and the results, and Section 5 presents the discussion on problematic issues. Section 6 provides the conclusions of the research.

\section{Literature review}

In the modern world, there are more than 200 sports. Each of them has its own subject of competition, a special set of actions, methods and rules. According to these characteristics, Matveev introduced the following classification. The first group includes sports, which are characterized with the athletes' active motor 
activity and the ultimate physical and mental abilities. This group includes most sports. The second group includes sports, which are based on the operation of special technical vehicles. The third group consists of the sports with motor activity of hitting a target with special weapons. The fourth group comprises sports that are based on the comparison of the results of the athlete's modelling and design activity. The fifth group includes the types of sports, the main content of which is determined through the competitions by means of the abstract-logical beating of the opponent. The sixth group is formed with the all-rounds, combining sports disciplines from various groups (Matveev, 2019).

A competitive activity of an athlete or a team always has a quantitative assessment. It represents sports result and is determined by the following specified factors: metric measurement, subjective referee's assessment, final effect combined with a time factor, athlete's satisfaction, etc. (Malcata \& Hopkins, 2014; Matveev, 2019).

The most significant indicator that influences the dynamics of individual sports achievements is the effectiveness of the athlete training system. It depends on the following: recent scientific data, methodological models and recommendations applied for the training; methods and means of athletes' recovery; the quality of the equipment, clothes, shoes, protective devices, exercise machines of various designs and functions; the improvement of the system of tactics and training (Kim, Do Kim \& Lee, 2019; Yagodin, 2016).

It is necessary to point out some characteristics and features of sports achievements. Sport at any level tends for the top results or achievements that allow us to evaluate the safety margin of both an individual athlete and the team or community of people as a whole (Gill, 1986). The efficiency in sport is indicated through the results, that can be presented with a win over an opponent (score in points, goals); with absolute quantitative indicators (time, weight, distance); with qualitative motor combinations, etc. Another feature is a time period during which only some outstanding athletes can achieve the highest absolute performance in sports. However, after a few years, these results become achievable for a large number of athletes (Malcata \& Hopkins, 2014; De Bosscher, De Knop, van Bottenburg, Shibli \& Bingham, 2009).

The factor of "sports achievements" is determined by the athlete's individual abilities. On the other hand, sport and its effectiveness depend on the degree of preparedness for sport achievements, the presence of qualified personnel and socio-economic support of a sports organization, the implementation of effective training and competitive systems, the understanding of the importance of social and personal sports activities (Kim, Do Kim \& Lee, 2019; De Bosscher, De Knop, van Bottenburg, Shibli \& Bingham, 2009).

According to the analysis of these resources, it was possible to identify factors that characterize the athlete's individual achievements (Table 1).

The resource: (Kim, Do Kim \& Lee, 2019; Matveyev, 2019; Yagodin, 2016; Malcata \& Hopkins, 2014; De Bosscher, De Knop, van Bottenburg, Shibli \& Bingham, 2009).

The factors classified by level and introduced in the table determine the athlete's personal performance. Therefore, these indicators can be used for the athlete's competitiveness assessment. 
Table 1. Factors influencing the athletes' competitiveness.

\begin{tabular}{|c|c|}
\hline The title of the $1^{\text {st }}$ level factor (attribute) & The reason for the $2^{\text {nd }}$ level the factor(s) (attribute) \\
\hline 1. Sport & $\begin{array}{l}\text { The subject of the competition; } \\
\text { The characteristics of the motor activity. }\end{array}$ \\
\hline 2. Peculiarities of sports result identification & $\begin{array}{l}\text { Measurement in metric units; } \\
\text { Subjective assessment in nominal units; } \\
\text { Identification of the final effect (score); } \\
\text { Combined assessment. }\end{array}$ \\
\hline $\begin{array}{l}\text { 3. The efficiency of the athlete's training } \\
\text { system }\end{array}$ & $\begin{array}{l}\text { Training methodology and the presence of sports } \\
\text { personnel; } \\
\text { Rationality of the competition system; } \\
\text { Facilities and resources base; } \\
\text { Methodological base; } \\
\text { Biomedical base; } \\
\text { Information base. }\end{array}$ \\
\hline 4. Sports achievements & $\begin{array}{l}\text { Athlete's individual abilities; } \\
\text { The degree of preparedness for sport achievements } \\
\text { The presence of sports personnel; } \\
\text { Socio-economic and legal support of a sports } \\
\text { organization. }\end{array}$ \\
\hline
\end{tabular}

\section{MATERIALS AND METHODS}

The authors of the present study declare that the problem of the athletes' competitiveness assessment can be solved with the development of an integral model, which can be introduced with Formula 1.

$$
\begin{aligned}
& C=\sum_{i=1}^{m}\left[r_{i} \cdot\left(\sum_{j=1}^{n} x_{i j}\right)\right]=\sum_{i=1}^{m}\left[r_{i} \cdot X_{i j}\right] \\
& 0<x_{i j} \leq a \\
& r_{i} \cdot X_{i j} \rightarrow \max
\end{aligned}
$$

Where:

$\mathrm{C}$ is the competitiveness coefficient of a team or sports organization as a whole;

Each summand (ri-Xij) is the resulting function or competitiveness coefficient of the i-th individual athlete or the i-th team member;

$r_{i}$ is individual rank multiplier or significance coefficient of the i-th athlete or the i-th team member;

$x_{i j}$ is standard $\mathrm{j}$-th factor for the $\mathrm{i}$-th athlete or the i-th team member;

$a$ is a constraint for the standard factors.

To identify the individual rank multiplier ri, corresponding to the i-th player or team member, Formula 2 is implemented: 
$r_{i}=\frac{R_{i}}{\sum_{i} R_{i}} \cdot 10$

Where:

$\mathrm{Ri}$ is the rank of the $\mathrm{i}$-th athlete or the $\mathrm{i}$-th team member.

The value of the individual rank multiplier $(0<\mathrm{ri}<10)$ is determined by the significance level in accordance with Table 2.

Table 2. Rank multiplier scale.

\begin{tabular}{ll}
\hline Rank multiplier value & Significance level characteristic \\
\hline $0<\mathrm{ri}<0.1$ & Inessential level of significance \\
\hline $0.1<\mathrm{ri}<0.5$ & Low level of significance \\
\hline $0.5<\mathrm{ri}<1$ & Moderate level of significance \\
\hline $1<\mathrm{ri}<3$ & Medium level of significance \\
\hline $3<\mathrm{ri}<5$ & High level of significance \\
\hline $5<\mathrm{ri}<10$ & Significance level is very high \\
\hline & Note: The resource (developed by the authors).
\end{tabular}

Rank multipliers ${ }^{r_{i}}$ show the significance level of the corresponding i-th athlete (team member). They are formed with the statistical data in scores that reflect the athlete's achievements. These data are recorded by trainers, instructors and other employees of sports organizations during training, performances and competitions. Consequently, they are included into the reports that are provided to the head of the sports club, to higher sports organizations, federations, etc. The reliability of the model is determined by the objectivity of the indicators.

Competitiveness analysis within a sports organization can be performed in various areas, such as: for each athlete individually; for the athlete's position in team sports; for team as a whole; for sports that are presented in the organization, etc. (Shavandina, Vasilev, Philippova \& Kiryushina, 2019).

Non-parametric Wilcoxon test can be applied in order to determine the qualitative change in the individual data of athletes or team members at the beginning and at the end of the sports season or another time interval. This criterion is implemented in order to assess the differences between two dependent samples, which are measured with an ordinal scale. In our case, the athlete's individual results are quantified and ranked. The rank criterion is invariant with respect to any monotone transformation of the measurement scale (Hollander, Wolfe \& Chicken, 2014; Corder \& Foreman, 2014).

Individual results of a team members form the sample for applying the non-parametric Wilcoxon criterion. According to individual indicators at the beginning ( $t_{\text {before}}$ ) and at the end ( $t_{\text {after }}$ ) of the period, we introduce the hypothesis of a zero median. For this method, it is necessary:

- To determine the ranks, corresponding to the difference of individual indicators in atypical direction,

- To calculate their (ranks') sum T.

Tcr for the sample is defined in accordance with the table "Applications for the Wilcoxon test". If Temp is less than or equal to Tcr, then a shift to the "typical" side reliably prevails. Otherwise, the hypothesis of a zero 
median is rejected (Hollander, Wolfe \& Chicken, 2014; Corder \& Foreman, 2014). This mathematical method can be applied on the base of Microsoft Office Excel (Egoshin, Ivanov, Savvina, Kalmakhanov, Zhamaliyeva \& Grjibovski, 2018; Grjibovski, Ivanov, Gorbatova, 2016).

\section{RESULTS}

The empirical level of scientific knowledge allows us to perform integrated modelling, targeted to assess the factors influencing the athletes' competitiveness. Methods of economic and mathematical modelling with statistical elements were implemented in order to adjust the research methodology for these attributes / factors.

The analysis of the competitiveness of the team members is conducted using the athletes' individual data of the " $U$ " club, which were prepared by the trainers for a statistical report to a superior sports organization. We should note that the volleyball club " $U$ " plays in the Premier League "A" and is the winner and awardee of the Spartakiad of the Peoples of Siberia. It is a non-profit physical education and sports organization. The club consists of a manager, i.e., the head coach, the senior coach and 14 players, namely: 7 forwards, 2 passers, 3 blockers and 2 liberos.

To calculate the competitiveness coefficient for the i-th team member, we use the factors introduced in Table 1 as the attributes that influence the resulting function. At the initial stage, the sports activities of 14 players and 4 factors were analysed (Table 1). Therefore, the integral model will be developed as the following (3):

$$
\begin{aligned}
& C=\sum_{i=1}^{14}\left[r_{i} \cdot\left(\sum_{j=1}^{4} x_{i j}\right)\right]=\sum_{i=1}^{14}\left[r_{i} \cdot X_{i j}\right] \\
& 0<x_{i j} \leq a \\
& r_{i} \cdot X_{i j} \rightarrow \max
\end{aligned}
$$

Where:

$i=\overline{1 ; 14}$ is the number of players / team members;

$j=\overline{1 ; 4}$ is the number of main factors influencing, each athlete's individual competitiveness;

$a$ - is the maximum scores that the i-th athlete can get for the period.

According to the results of the monitoring conducted by the trainers, individual rank multipliers ${ }^{r_{i}}$ for each team member were calculated and introduced in Table 3. It is worth highlighting that the highest rank is assigned to the athlete with the greatest scores of individual indicators.

The calculation results contribute to the following conclusions:

- Individual indicators are almost equally distributed among the team members: from 185 to 220 scores. On average, there is a lag of 2.5 scores $(1.1 \%)$ between neighbouring individual indicators. This means that team members are in almost the same competition form. There is no significant difference in skill between the athletes.

- Despite the fact that this is a team sport, we can define the leaders. These athletes have the highest individual indicators, which were demonstrated not only during the championship, but also during the 
training period. The data of these team members are introduced at the top of Table 3. The values of these athletes' individual rank multipliers exceed 1, which determines their competitiveness.

- Half of the team members have the value of an individual rank multiplier ranging from 0.5 to 1 . This group includes different athletes, such as: forwards, blockers, liberos, and passers. Therefore, $50 \%$ of the athletes of the team have identical level of significance and compete with each other, having equal athletic achievements.

Table 3. The level of individual significance of the club "U" athletes.

\begin{tabular}{lllllll}
\hline $\begin{array}{l}\text { Athlete's } \\
\text { Individual } \\
\text { Number }\end{array}$ & $\begin{array}{l}\text { Information } \\
\text { about the } \\
\text { athlete }\end{array}$ & $\begin{array}{l}\text { Athlete's } \\
\text { individual } \\
\text { results, } \\
\text { score }\end{array}$ & $\begin{array}{l}\text { Rank } \\
\text { Ri }\end{array}$ & $\begin{array}{l}\text { Rank } \\
\text { multiplier } \\
\text { Ri }\end{array}$ & $\begin{array}{l}\text { Significance } \\
\text { level }\end{array}$ & $\begin{array}{l}\text { Athlete's } \\
\text { competitiveness } \\
\text { coefficient, } \\
\text { score }\end{array}$ \\
\hline 1 & 2 & 3 & 4 & 5 & 6 & 7 \\
\hline 1 & forward & 220 & 10 & 1.4 & Medium & 308 \\
\hline 2 & libero & 215 & 9 & 1.2 & Medium & 258 \\
\hline 3 & passer & 213 & 8 & 1.1 & Medium & 233.2 \\
\hline 4 & forward & 210 & 7 & 0.9 & Moderate & 189 \\
\hline 5 & forward & 210 & 7 & 0.9 & Moderate & 189 \\
\hline 6 & libero & 204 & 6 & 0.8 & Moderate & 163.2 \\
\hline 7 & passer & 199 & 5 & 0.7 & Moderate & 139.3 \\
\hline 8 & blocker & 199 & 5 & 0.7 & Moderate & 139.3 \\
\hline 9 & forward & 199 & 5 & 0.7 & Moderate & 139.3 \\
\hline 10 & blocker & 195 & 4 & 0.5 & Moderate & 97.5 \\
\hline 11 & forward & 194 & 3 & 0.4 & Low & 77.6 \\
\hline 12 & blocker & 190 & 2 & 0.3 & Low & 57 \\
\hline 13 & forward & 190 & 2 & 0.3 & Low & 57 \\
\hline 14 & forward & 185 & 1 & 0.1 & Low & 18.5 \\
\hline & & $\Sigma=2823$ & $\Sigma=74$ & $\Sigma=10$ & & $\Sigma=1918.9$ \\
\hline
\end{tabular}

According to the data from Table 3, the integrated model for calculating the competitiveness coefficient will be written as the following (4):

$$
\begin{aligned}
C= & 1,4 \times 1 j+1,2 \times 2 j+1,1 \times 3 j+0,9 \times 4 j+0,9 \times 5 j+0,8 \times 6 j+0,7 \times 7 j+0,7 \times 8 j+ \\
& +0,7 \times 9 j+0,5 \times 10 j+0,4 \times 11 j+0,3 \times 12 j+0,3 \times 13 j+0,1 \times 14 j
\end{aligned}
$$

Each summand of the integral model is an indicator of the competitiveness of a particular team member. The quantitative assessment of this coefficient is introduced in column 7 of Table 3 . If the individual rank multiplier ri $>1$, it enhances the competitiveness coefficient (athletes with individual numbers 1-3), increasing the corresponding athlete's significance. Otherwise, if ri $<1$, the significance decreases due to the influence of the rank multiplier and causes a decrease in the competitiveness indicator of a team member (athletes with individual numbers 4-14). The largest summand in the value of the integral model $C$ identifies the most competitive athlete of the team, determines the effectiveness of his competition form, as well as higher sports achievements.

In the sports club "U", the forward with individual number 1 has the highest competitiveness coefficient of 308 scores, which exceeds the corresponding indicator of the forward number 14 more than 16 times. The range 
of the coefficients is quite wide, i.e., from 18.5 points to 308 points. The largest percentage gap of $308 \%$ is observed between the athletes with numbers 13 and 14 . This is due to the low value of the rank multiplier, which influences the decrease in the individual indicator. On the other hand, the gap between the individual indicators of athletes with numbers $7-9$ and a blocker with number 10 is only 2 points. The percentage gap in competitiveness coefficient is $42 \%$, despite the fact that the significance level is the same.

The authors implemented nonparametric Wilcoxon test to determine the qualitative change in the individual data of the "U" club athletes at the beginning of a certain time interval (tbefore) and at the end (tafter).

The following is taken as the hypothesis:

$\mathrm{HO}$ : the values after the experiment exceed the values before the experiment.

All the necessary data and calculation results are introduced in Table 4.

Table 4. The final statistical table for the Wilcoxon criterion for the "U" club athletes.

\begin{tabular}{lllll}
\hline $\begin{array}{l}\text { At the beginning of } \\
\text { the period }\end{array}$ & $\begin{array}{l}\text { At the end of } \\
\text { the period }\end{array}$ & Difference & $\begin{array}{l}\text { Absolute Value of the } \\
\text { difference }\end{array}$ & $\begin{array}{l}\text { Rank number of the } \\
\text { difference }\end{array}$ \\
\hline 220 & 225 & 5 & 5 & 13.5 \\
\hline 215 & 219 & 4 & 4 & 11.5 \\
\hline 213 & 212 & -1 & 1 & 5.5 \\
\hline 210 & 210 & 0 & 0 & 1.5 \\
\hline 210 & 212 & 2 & 2 & 9.5 \\
\hline 204 & 202 & -2 & 2 & 9.5 \\
\hline 199 & 200 & 1 & 1 & 5.5 \\
\hline 199 & 198 & -1 & 1 & 5.5 \\
\hline 199 & 200 & 1 & 1 & 5.5 \\
\hline 195 & 199 & 4 & 4 & 11.5 \\
\hline 194 & 193 & -1 & 1 & 13.5 \\
\hline 190 & 195 & 5 & 5 & 5.5 \\
\hline 190 & 189 & -1 & 1 & 1.5 \\
\hline 185 & 185 & 0 & 0 & 105 \\
\hline Sum & & & & \\
\hline
\end{tabular}

The sum of the rank column is $\Sigma=105$.

The authors check the adequacy of the matrix development through the calculation of the checksum using the above formula:

$$
\sum x_{i j}=\frac{(1+n) \cdot n}{2}=\frac{(1+14) \cdot 14}{2}=105
$$

Where $n=14$ is a number of the team members.

The sum in the column and the checksum coincided. Therefore, the ranking was performed correctly. 
The next step is to define the areas that are atypical, i.e., negative. In Table 4, these directions and the corresponding ranks are highlighted. The sum of the ranks of these rare directions corresponds to the empirical value of the criterion Temp:

Temp $=\sum \mathrm{Rt}=5.5+9 \cdot 5+5 \cdot 5+5 \cdot 5+5.5=31.5$

According to the table "Applications for the Wilcoxon test" for $n=14$, receive the following:

$\operatorname{Tcr}=15(p \leq .01) \operatorname{Tcr}=25(p \leq .05)$

In this case, the empirical value of Temp $=31.5$ falls into insignificance zone: $\operatorname{Temp}>\operatorname{Tcr}(0.05)$. Hypothesis $\mathrm{H} 0$ is rejected. The indicators after the experiment do not exceed the values before the experiment (Hollander, Wolfe \& Chicken, 2014; Corder \& Foreman, 2014).

The results contribute to the conclusion that at the end of the period there were no significant changes in the athletes' individual indicators. Definitely, the data for 7 athletes increased slightly, and this is half of the team. Individual indicators of other team members either did not change at the end of the period or became worse.

There can be various reasons for this phenomenon:

- A short time interval for the analysis of individual indicators;

- The necessity to change the training schedule;

- The fatigue and burnout syndrome by the end of the sports season;

- Injuries during the analysed period.

The obtained results of nonparametric statistics cause minor changes (which can be neglected) in the assessment of the competitiveness of team members. According to the economic understanding of the Wilcoxon criterion, there is no need to count each athlete's competitiveness at the end of the period, since the changes are insignificant. On the other hand, this indicates the existing reserves that can be activated using the individual resources of team members and the capabilities of a sports organization.

\section{DISCUSSION}

The main purpose of the law is to regulate existing social relations, including economic, political, social, etc.

In different countries, the procedure of sports legal regulation is unique and differs from the Russian one.

Some researchers note that, despite the steady development of sports law and policy in European Union $(E U)$, the most relevant issues relate to the scope and content of sports exceptions, i.e., the special attitude to sport when applying the economic provisions of the EU, due to particular characteristics of this sector. In this context, the defined exceptions depend on the characteristics of the restriction, the economic effect and the applicable rules (Pijetlovic, 2017). As Pijetlovic notes, the model of self-government of sports federations in Europe, characterized with the certain degree of legal, financial and political autonomy, allows them to organize and regulate their sport as they consider it necessary. However, this legal and financial freedom depends on their compliance with EU legislation. On the other hand, it is worth highlighting that sport complies with EU laws "only insofar as it is an economic activity" (Pijetlovic, 2017; Schulenkorf, 2017). 
Some researchers point out that the activity of EU is restricted by the Contract and does not have explicit powers in the field of sport. In other words, the EU cannot influence the sport control bodies, although it receives some supervisory jurisdiction according to the relevant EU trade law. In this case, sports management becomes a subject of the study of EU law (Weatherill, 2014; Peachey, Schulenkorf, Hil, 2019).

Another group of scientists studies the comparative aspect of sports law at the international level. They note that professional sport consists of national organizations for each sport, which are included into continental and global federations. The rules of professional sports are transnational. Therefore, there is a single legal order with integrated national and international levels. However, it does not mean that international rules and norms are copied at the regional level due to the hierarchy. Countries may have similar social systems in general, but completely different sports systems with adequate legal regulation (Siekmann \& Soek, 2012; Van Kleef, 2014).

The next relevant issue of the legal regulation of sports relations is sports management. Sports management can be studied in terms of state intervention. Some states determine the general political and legal trends in sport and its financial support, while the others manage or monitor sports organizations. Therefore, the state determines the degree of legal regulation and financial support of sports organizations (De Dycker, 2019; Di Marco, 2019; Porter, 2016).

Russian scientists focus on the specificity, complexity and diversity of physical education and sports and emphasize the necessity of the development of the legal regulation of sports relations. This industry is the most dynamically developing in the Russian Federation, which determines a closer attention from the state and society (Alekseev, 2018; Gosteva, 2018; Korchagin, 2015; Bratanovsky, Vulakh, 2015; Saraev, 2019).

Iglin proposes to cooperate with EU countries in order to systematize the legislative framework. This involves the development of legal norms compatible with European countries, the use of international experience to formulate sports legislation of the Russian Federation, etc. (Iglin, 2014).

Nowadays, sport is a complex system depending on the collaboration of the state and the sports community. Legal regulations determine the legislative character of public (sports) relations, which consist of the subjects, object and content. Competitiveness is the most important characteristic of the subject of sports relationship, i.e. an athlete. To ensure the competitiveness of athletes and Russian sports in general, it is necessary to create conditions (financial and sports infrastructure) to improve athletic preparedness. According to Voevodina, this will contribute to athletes' competitiveness improvement (Voevodina, 2018).

Another aspect of the legal regulation of sports relations concerns the competitive moment and determines the necessity to register and prove sports achievements. A large number of scientists are engaged in the development of new high-tech analytical and diagnostic systems and complexes for training athletes, information databases for monitoring the athlete's condition, testing equipment for monitoring the athlete's functional state and equipment (Beanland, 2014; Callaway, 2014; Koryagina, Nopin, Blinov \& Blinov, 2015; Ohtonen, Ruotsalainen, Mikkonen, Heikkinen, Hakkarainen, Leppävuori \& Linnamo, 2015). However, these developments contribute to sports achievements, although do not quantify their (athletes') competitiveness.

\section{CONCLUSION}

The special character of the sports relations determines the peculiarity of legal regulation. It combines the centralized legislative regulation and local regulation by means of developing the standards at the level of 
sports federations, as well as contractual regulation at the level of individual subjects of sports relations. Moreover, the priority of a competent model of legal regulation of sports relations is to ensure a proper balance of the state interests and other subjects of sports relations (athletes, coaches, sports organizations, etc.). Thus, along with mandatory rules that provide the necessary restrictions in the field of sports, the legislator provides freedom to establish specific local and individual norms that reflect the specifics of a particular sport and the uniqueness of each individual legal relationship (labour law, civil law, social law, etc.). Currently, the athlete's competitiveness, that determines the competitiveness of the team and the sports organization as a whole, is the most important characteristic of the legal status of this subject of sports relations. However, this element has not been analysed properly within the framework of legal and economic aspects.

The promotion of athletes and sports organizations within the country and in the international arena requires adequate legal support. Therefore, the authors of the present work emphasize the necessity to enhance the system of legal regulation of sports relations through the athletes and organizations' competitiveness assessment.

\section{ACKNOWLEDGMENTS}

The study was carried out with the financial support of The Russian Foundation for Basic Research (scientific project No. 20-011-00053 A "Legal regulation of sports relations in the Russian Federation").

The authors acknowledge the Russian Foundation for Basic Research for theoretical research support on the most relevant problems in various fields of science.

The authors are grateful to the experts for their in-depth analysis of the work submitted for review. The recommendations were valuable, and as the researchers hope, have helped to improve the manuscript.

\section{REFERENCES}

Alekseev, S.V. (2018). Sports Law. Moscow. Russia. YuNITI-DANA: Law and Justice.

Beanland, E. (2014). Validation of GPS and accelerometer technology in swimming. Journal of Science and Medicine in Sport. 17 (2). 234-238.

Bratanovsky, S.N., Vulakh, M.G. (2015). Physical culture and sports organizations (FCSO) as the subjects of administrative-legal relations. Sports: Economics, Law, Management. 1, 14-19.

Callaway, A. (2014). Quantification of performance analysis factors in front crawl using micro electronics: a data rich system for swimming. Doctorate Thesis (Doctorate). Bournemouth University.

Corder, G.W., Foreman, D.I. (2014) Nonparametric Statistics: A Step-by-Step Approach-Wiley. - ISBN 978-1118840313.

De Bosscher, V., De Knop, P., van Bottenburg, M., Shibli, S., Bingham, J. (2009) Explaining international sporting success: An international comparison of elite sport systems and policies in six countries Sport Management Review 12(3), 113-136. https://doi.org/10.1016/j.smr.2009.01.001

De Dycker, S. (2019) Good governance in Sport: comparative law aspects. Int Sports Law J 19, 116128. https://doi.org/10.1007/s40318-019-00153-8

Di Marco, A. (2019) The internal governance of sporting organizations: international convergences on an idea of democracy. Int Sports Law J 19, 171-183. https://doi.org/10.1007/s40318-019-00144-9

Egoshin, V.L., Ivanov, S.V., Savvina, N.V., Kalmakhanov, S.B., Zhamaliyeva, L.M., Grjibovski, A.M. (2018). Analysis of Continuous Data Using R. Ekologiya cheloveka [Human Ecology]. 11, 51-64. 
Gill, D.L. (1986) Competitiveness among females and males in physical activity classes. Sex Roles 15, 233-247. https://doi.org/10.1007/bf00288314

Gosteva, S.R. (2018). Legislative framework for the development of physical culture and sports in the Russian Federation. Eurasian Forum. 1 (10), 241-257.

Grjibovski, A.M., Ivanov, S.V., Gorbatova, M.A. (2016). Comparison of quantitative data of two independent samples using Statistica and SPSS software: parametric and nonparametric criteria. Science and healthcare. 2, 5-28.

Hollander, M., Wolfe, D.A., Chicken, E. (2014). Nonparametric Statistical Methods, John Wiley \& Sons. Iglin, A.V. (2014). Actual problems of European Sports Law. Sport: Economics, Law, Management. 1, 39-40.

Kim, M., Do Kim, Y., Lee , H-W (2019) It is time to consider athletes' well-being and performance satisfaction: The roles of authentic leadership and psychological capital. Sport Management Review. https://doi.org/10.1016/j.smr.2019.12.008

Korchagin, E.V. (2015). Legal status of a sports federation as a self-regulatory organization in terms of changes in civil legislation on legal entities. Lawyer. 18. 36-4.

Koryagina, Yu.V., Nopin, S.V., Blinov, V.A., Blinov, O.A. (2015). "Exergames" technology as an innovative means of sports training and athletes 'performance testing (based on foreign literature). Contemporary problems of science and education, 4.

Malcata, R.M., Hopkins, W.G. (2014) Variability of Competitive Performance of Elite Athletes: A Systematic Review. Sports Med 44, 1763-1774. https://doi.org/10.1007/s40279-014-0239-x

Matveev, L.P. (2019). General theory of sports and its applied aspects. Moscow. Russia. "Sport" Publishing House.

Ohtonen, O., Ruotsalainen, K., Mikkonen, P., Heikkinen, T., Hakkarainen, A., Leppävuori, A., Linnamo, V. (2015). Online feedback system for athletes and coaches. 3rd International Congress on Science and Nor-dic Skiing. Vuokatti, Finland. Vuokatti Sports Institute.

Peachey, J.W., Schulenkorf, N., Hil, P. (2019). Sport-for-development: A comprehensive analysis of theoretical and conceptual advancements Sport Management Review. https://doi.org/10.1016/j.smr.2019.11.002

Pijetlovic, K. (2017) EU sports law: a uniform algorithm for regulatory rules. Int Sports Law J 17, 86-100. https://doi.org/10.1007/s40318-017-0114-7

Porter, M.E. (2016). Competitive strategy: Methodology for analyzing industries and competitors. Moscow. Alpina Publisher.

Saraev, V.V. (2019). On the matrix of fundamental legal concepts of industry objects in the context of commercial of relations in the sphere of physical education and sports. Sports: economics, law, management. 3, 25-29.

Schulenkorf, N. (2017). Managing sport-for-development: Reflections and outlook Sport Management Review. 20. 243-251. https://doi.org/10.1016/j.smr.2016.11.003

Shavandina, O., Vasilev, A., Philippova, T., Kiryushina, I. (2019). Multidimensional Analysis of Factors Affecting Students' Employment. Opcion: Revista de Ciencias Humanas y Sociales. 35. Especial $\mathrm{N}^{\circ} 21.816-832$.

Shchepakin, M.B., Krivosheeva, E.V. (2015). Managing of enterprise competitiveness in terms of the market environment changing. International research journal. 9 (40). Part 1. 81-84.

Siekmann R.C.R., Soek J. (2012) Towards a Typology of (International) Comparative Sports Law (Research). In: Siekmann R., Soek J. (eds) Lex Sportiva: What is Sports Law? ASSER International Sports Law Series. T. M. C. Asser Press. https://doi.org/10.1007/978-90-6704-829-3 17

Van Kleef, R. (2014) The legal status of disciplinary regulations in sport. Int Sports Law J 14, 24-45. 
Voevodina, S.S. (2018). Management aspects of athletes' competitiveness improvement. Resources of athletes' competitiveness: the theory and practice of implementation 1, 53-55.

Weatherill S. (2014). The Influence of EU Law on Sports Governance. In: European Sports Law. ASSER International Sports Law Series. T.M.C. Asser Press, The Hague. https://doi.org/10.1007/978-906704-939-9 17

Yagodin, V.V. (2016). Fundamentals of sports ethics. Yekaterinburg. Russia. Publishing House of Ural University. 